\title{
Lusioersily
}

\section{Targeted Chemo-Sonodynamic Therapy Treatment of Breast Tumours Using Ultrasound Responsive Microbubbles Loaded with Paclitaxel, Doxorubicin and Rose Bengal.}

Callan, J., Logan, K., Foglietta, F., Nesbitt, H., Sheng, Y., McKaig, T., Kamila, S., Gao, J., Nomikou, N., Callan, B., \& McHale, A. P. (2019). Targeted Chemo-Sonodynamic Therapy Treatment of Breast Tumours Using Ultrasound Responsive Microbubbles Loaded with Paclitaxel, Doxorubicin and Rose Bengal. European Journal of Pharmaceutics and Biopharmaceutics, 139, 224-231. https://doi.org/10.1016/j.ejpb.2019.04.003

Link to publication record in Ulster University Research Portal

Published in:

European Journal of Pharmaceutics and Biopharmaceutics

Publication Status:

Published (in print/issue): 01/06/2019

DOI:

10.1016/j.ejpb.2019.04.003

Document Version

Author Accepted version

\section{General rights}

Copyright for the publications made accessible via Ulster University's Research Portal is retained by the author(s) and / or other copyright owners and it is a condition of accessing these publications that users recognise and abide by the legal requirements associated with these rights.

\section{Take down policy}

The Research Portal is Ulster University's institutional repository that provides access to Ulster's research outputs. Every effort has been made to ensure that content in the Research Portal does not infringe any person's rights, or applicable UK laws. If you discover content in the Research Portal that you believe breaches copyright or violates any law, please contact pure-support@ulster.ac.uk. 


\section{Targeted Chemo-Sonodynamic Therapy Treatment of Breast Tumours Using Ultrasound Responsive Microbubbles Loaded with Paclitaxel, Doxorubicin and Rose Bengal.}

Keiran Logan', Federica Foglietta ${ }^{1}$, Heather Nesbitt ${ }^{1}$, Yingjie Sheng ${ }^{1}$, Thomas McKaig ${ }^{1}$, Sukanta Kamila ${ }^{1}$, Jinhui Gao ${ }^{1}$, Nikolitsa Nomikou ${ }^{2}$, Bridgeen Callan ${ }^{1}$, Anthony P. McHale ${ }^{1}$ and John F. Callan'1.

1. Biomedical Sciences Research Institute, University of Ulster, Coleraine, Northern Ireland, U.K. BT52 1SA. 2. Division of Surgery \& Interventional Science, Faculty of Medical Sciences, University College London, UK.

Abstract: Mastectomy is a common surgical treatment used in the management of breast cancer but has associated physical and psychological consequences for the patient. Breast conservation surgery (BCS) is an alternative to mastectomy but is only possible when the tumour is of an appropriate size. Neo-adjuvant chemotherapy has been successfully used to downstage tumours and increase the number of patients eligible for BCS. However, the chemotherapies used in this approach are non-targeted and often result in significant side effects to the patient. In this manuscript, we evaluate the potential of ultrasound targeted microbubble destruction (UTMD) to deliver Rose Bengal-mediated sonodynamic therapy (SDT) in combination with paclitaxel (PTX) and doxorubicin (Dox) chemotherapy as a potential treatment for breast cancer. Efficacy of the combined treatment was determined in a threedimensional (3D) spheroid model of human breast cancer and in a murine model of the disease bearing subcutaneous MCF-7 tumours. The results demonstrated a significant reduction in both the cell viability of spheroids and tumour volume following treatment with the drug loaded microbubbles and ultrasound compared to targets treated with the drug loaded microbubbles alone or a Cremophor EL suspension of PTX and Dox. In addition, the weight of animals that received the microbubble treatment was unchanged throughout the study while a reduction of $12.1 \%$ was observed for animals treated with a Cremophor suspension of 
PTX/Dox. These results suggest that UTMD-mediated chemo-sonodynamic therapy is an efficacious and well tolerated approach for the treatment of breast cancer.

Keywords: Chemotherapy, sonodynamic therapy, microbubbles, ultrasound targeted microbubble destruction, breast cancer, MCF-7.

1.0 Introduction: Breast cancer is the most prevalent form of cancer worldwide with 55,200 new cases reported in the UK alone in $2015 .{ }^{1}$ Mastectomy is a common treatment for breast cancer with approximately 19,000 mastectomy surgeries performed in the UK each year. ${ }^{2}$ As the physical and psychological effects of this treatment can be considerable, there is a growing need for more effective non-surgical treatments to reduce the overall mastectomy rate. Neoadjuvant chemotherapy has been used to downstage tumours in advance of surgery and enable their removal by less invasive lumpectomy. ${ }^{3,4}$ This approach has proven effective in increasing the number of patients eligible for breast conserving surgery without posing a risk to the overall or progression-free survival rate. ${ }^{5}$ However, the chemotherapies used in these regimens are non-targeted to tumour tissue and cause significant off-target effects. ${ }^{6}$

Ultrasound targeted microbubble destruction (UTMD) has emerged as a promising strategy for the site-specific delivery of drug payloads to solid tumours. ${ }^{7}$ Microbubbles (MB) are lipid or polymer stabilised gas filled microspheres that have found clinical use as contrast agents in diagnostic ultrasound (US) applications. At low acoustic pressures, the MBs resonate in a symmetric manner and this feature helps improve the quality of the US image. ${ }^{8}$ At higher acoustic pressures, inertial forces dominate resulting in microbubble collapse and ultimately destruction of the $\mathrm{MB} .^{9}$ When drug payloads are incorporated within the MB structure, they become deposited at the site of destruction. ${ }^{8}$ As US energy can be tightly focussed in three dimensions in human tissue, it is therefore possible to use UTMD to selectively deliver payloads to target sites with limited damage to surrounding tissue. ${ }^{9}$ 
We have previously demonstrated in pre-clinical experiments the utility of UTMD as an effective strategy for the delivery of chemotherapy and sonodynamic therapy (SDT) to pancreatic tumours. ${ }^{10}$ SDT is an emerging cancer treatment and involves the activation of an otherwise harmless sensitiser drug with low-intensity US to generate cytotoxic levels of reactive oxygen species (ROS). ${ }^{11-14}$ As oxygen is a key substrate for the generation of ROS in SDT, we have demonstrated that filling the core of MBs with oxygen gas enhances the ROS yield and SDT mediated cytotoxic effect observed. ${ }^{15}$ Our previous work has also shown that combining SDT with antimetabolite chemotherapy is more effective than either treatment alone at controlling the growth of pancreatic tumours. ${ }^{10,16}$ Moreover, by using UTMD as a drug delivery strategy, it was possible to achieve targeted delivery to the tumours and significantly reduce the overall amount of chemotherapy administered.

In this study, we adopted a similar approach using MBs to facilitate delivery of chemosonodynamic therapy for the treatment of breast cancer. Doxorubicin (Dox) and paclitaxel (PTX), which are commonly used in the management of breast cancer, were selected as chemotherapies while Rose Bengal (RB) was used as the SDT sensitiser. PTX is a notoriously hydrophobic drug with a $\operatorname{LogP}$ of approximately3.5 ${ }^{17}$ and was incorporated within the hydrophobic acyl chain layer of the MB shell, while the hydrophilic Dox was modified to include a biotin anchor that enabled its attachment to the MB surface using the biotin-avidin interaction. As in our previous work, a biotin derivative of RB was also prepared to facilitate attachment to the MB surface. ${ }^{11}$ The resulting MBs were characterised in terms of size, concentration and drug loading while the efficacy of MB mediated chemo-sonodynamic therapy was determined in a three-dimensional (3D) spheroid model of human breast cancer and in a murine model of the disease bearing subcutaneous MCF-7 tumours.

\subsection{Materials \& Methods.}

2.1 Reagents and Materials: 1,2-dibehenoyl-sn-glycero-3-phosphocholine (DBPC) and 1,2distearoyl-sn-glycero-3-phosphoethanolamine- $N$-[methoxy(polyethylene glycol)-2000] (DSPE-PEG(2000)) and DSPE-PEG(2000)-biotin were purchased from Avanti Polar Lipids 
(Alabaster, Alabama, USA). Avidin (Egg White) was purchased from Thermo Fisher Scientific (Waltham, Massachusetts, USA). Oxygen and nitrogen gas was purchased from BOC Industrial Gases (Guildford, UK)and perfluorobutane (PFB) was purchased from Apollo Scientific Ltd (Cheshire, UK). Phosphate Buffered Saline (PBS), streptomycin, Dulbecco's Modified Eagle's Medium (DMEM) and Propidium lodide (P.I.) were purchased from Thermo Fisher Scientific (Massachusetts, USA). Matrigel was purchased from Corning (New York, USA). Severe combined immunodeficient (SCID) (C.B-17/lcrHan®Hsd-Prkdcscid) mice were purchased from Charles River Laboratory (Massachusetts, USA). Paclitaxel and biotin were purchased from XABC (Xi'an, China). Doxorubicin was purchased from LC Laboratories (Boston, MA, USA). All other chemicals were purchased from Sigma Aldrich (Gillingham, UK) at the highest grade possible. MCF-7 cells were purchased from American Type Culture Collection (ATCC, Rockville, MD, USA). CellCarrier Ultra ULA-Coated 96-well Microplates were purchased from Perkin Elmer (Massachusetts, USA). Analytical HPLC analysis was undertaken using a Shimadzu HPLC (Shimadzu, Kyoto, Japan) fitted with an SPD-M20A photo-diode array detector and a Phenomenex $\mathrm{C}_{18}$ column (Phenomenex, California, USA) $(250 \times 4.6 \mathrm{~mm}, 5 \mu \mathrm{m})$. UV-Vis analysis was performed using a Varian-50 Bio UV-Visible spectrophotometer (Varian, California, USA). Optical microscope images were obtained using a Leica DM500 optical microscope (Leica, Wetzlar, Germany). MTT absorbance was analysed using a FLUOstar Omega microplate reader (BMG Labtech, Ortenberg, Germany). Fluorescence images were obtained using a NIKON Eclipse E400 Phase contrast microscope (Nikon, Tokyo, Japan) (540 nm band pass excitation and $590 \mathrm{~nm}$ long pass emission filters, respectively). NMR spectra were recorded on a Varian $500 \mathrm{MHz}$ spectrometer (Varian, California, USA). ESI-MS characterisation was achieved using a LCQTM quadrupole ion-trap mass spectrometer (Finnigan MAT, California, USA) utilising electrospray ionisation (ESI).

2.2 Synthesis of Biotin-Dox (5): Biotin-N-hydroxysuccinimide ester (3) was prepared by the reaction of biotin (1) and N,N-Disuccinimidyl carbonate (2) following a literature procedure. ${ }^{18}$ To an ice cold solution of $\mathbf{3},(0.14 \mathrm{~g}, 0.41 \mathrm{mmol})$ in DMF $(10 \mathrm{ml})$ was added doxorubicin (4, 
$0.3 \mathrm{~g}, 0.41 \mathrm{mmol})$ under a nitrogen atmosphere. After stirring for $30 \mathrm{~min}$, triethylamine $(0.5 \mathrm{ml}$, $2 \mathrm{mmol}$ ) was added to the reaction mixture and the contents stirred for $12 \mathrm{~h}$ at room temperature. The reaction was monitored by thin layer chromatography (TLC) (Merck Silica 60, HF 254, 20: 80 methanol-dichloromethane v/v). After completion of the reaction, excess diethyl ether $(100 \mathrm{ml})$ was added to the reaction mixture. The resultant red precipitate was filtered and washed three times with diethyl ether $(50 \mathrm{ml} X 3)$. The solid was then subjected to preparative thin layer chromatography (PTLC) purification (methanol-dichloromethane (20:80, $\mathrm{v} / \mathrm{v})$ ) to obtain $0.25 \mathrm{~g}($ Yield $=78 \%)$ of $5 .{ }^{1} \mathrm{H}$ NMR $\left(\right.$ DMSO- $\left._{6}\right) \delta: 7.84(\mathrm{~d}, \mathrm{~J}=7.5 \mathrm{~Hz}, 2 \mathrm{H}$, aromatic), $7.58(\mathrm{~d}, \mathrm{~J}=7.5 \mathrm{~Hz}, 1 \mathrm{H}$, aromatic), $6.36(\mathrm{~s}, 1 \mathrm{H}, \mathrm{NH}), 6.29(\mathrm{~s}, 1 \mathrm{H}, \mathrm{NH}), 5.37(\mathrm{brs}, 1 \mathrm{H}$, $\mathrm{OH}), 5.22$ (brs, $1 \mathrm{H}, \mathrm{OH}), 4.87\left(\mathrm{~s}, 2 \mathrm{H},-\mathrm{CH}_{2}-\mathrm{OH}\right), 4.51$ (brs, $\left.2 \mathrm{H}, \mathrm{OH} \times 2\right), 4.36-4.33(\mathrm{~m}, 1 \mathrm{H}$, $\mathrm{CH}), 4.25-4.22(\mathrm{~m}, 1 \mathrm{H}, \mathrm{CH}), 4.16-4.13(\mathrm{~m}, 1 \mathrm{H}, \mathrm{CH}), 3.99\left(\mathrm{~s}, 3 \mathrm{H}, \mathrm{OCH}_{3}\right), 3.60-3.58(\mathrm{~m}, 1 \mathrm{H}$, $\mathrm{CH}), 3.55$ (brs, $2 \mathrm{H}, \mathrm{OH} X 2)$, 3.10-3.00 (m, 4H, $\left.\mathrm{CH}_{2} \mathrm{X} 1, \mathrm{CH} X 2\right), 2.88-2.54\left(\mathrm{~m}, 3 \mathrm{H}, \mathrm{CH}_{2} \mathrm{X} 1\right.$, $\mathrm{CH}), 2.20-2.00(\mathrm{~m}, 1 \mathrm{H}, \mathrm{CH}), 1.63-1.50\left(\mathrm{~m}, 4 \mathrm{H}, \mathrm{CH}_{2} \mathrm{X} 2\right), 1.42-1.22\left(\mathrm{~m}, 11 \mathrm{H}, \mathrm{CH}_{3} \mathrm{X} 1, \mathrm{CH}_{2} \mathrm{X}\right.$ 4). ${ }^{13} \mathrm{CNMR}\left(\mathrm{DMSO}-\mathrm{d}_{6}\right): 177.6,176.9,174.8,166.4,163.0,161.2,153.7,152.7,137.4,132.4$, $120.4,119.4,99.5,97.8,80.15,75.1,72.7,66.4,61.4,59.5,55.7,47.8,33.8,31.9,28.9,28.8$, 28.5, 28.4, 24.9, 19.8, 17.6, 17.1. Negative mode electrospray mass spectrum: ESI-MS [M$\mathrm{H}]$ : calculated for $\mathrm{C}_{37} \mathrm{H}_{43} \mathrm{l}_{2} \mathrm{~N}_{3} \mathrm{O}_{13} \mathrm{~S}=769 \mathrm{Da}$, found = $768 \mathrm{Da}$.

\subsection{Preparation of oxygen carrying microbubbles loaded with PTX in the shell and}

biotin-Dox or biotin-RB attached to the MB surface: Avidin-functionalised PTX-loaded MB were prepared by first dissolving 1,2-dibehenoyl-sn-glycero-3-phosphocholine (DBPC) (4.0mg, 4.44umol), 1,2-distearoyl-sn-glycero-3-phosphoethanolamine- N[methoxy(polyethylene glycol) -2000] (DSPE-PEG(2000)) (1.35mg, 0.481umol) and 1,2distearoyl-sn-glycero-3-phosphoethanolamine-N-[biotinyl(polyethylene glycol)-2000] (ammonium salt) (DSPE-PEG (2000)-biotin) (1.45mg, 0.481umol) in chloroform to achieve a molar ratio of $82: 9: 9$. To this solution was added paclitaxel $(7,5 \mathrm{mg}, 5.86 \mu \mathrm{mol})$ dissolved in chloroform $(100 \mu \mathrm{L})$. The solvent was removed under vacuum at room temperature yielding a translucent film. The film was then reconstituted in $2 \mathrm{~mL}$ of a solution containing PBS, glycerol 
and proplyene glycol (8:1:1 volume ratio) and heated in a water bath at $80^{\circ} \mathrm{C}$ for $30 \mathrm{~min}$. The suspension was sonicated using a Microson ultrasonic cell disrupter at an amplitude of $22 \%$ for $1 \mathrm{~min}$ and then at an amplitude of $90 \%$ in a perflourobutane (PFB) atmosphere for $30 \mathrm{sec}$. The MBs were then cooled on ice for $10 \mathrm{~min}$ followed by centrifugation at $100 \mathrm{rcf}$ for $3 \mathrm{~min}$ and the liquid laying below the surface of the MB cake (infranatant) was removed. The PTX-MB cake was then washed a further 2 times with PBS $(\mathrm{pH} 7.4 \pm 0.1)$ before being mixed for 5 min on ice with an aqueous solution of avidin $(10 \mathrm{mg} / \mathrm{mL})$ using an orbital shaker (150 rpm). The PTX-MBs were then centrifuged (100 rcf) for $3 \mathrm{~min}$, the infranatant removed and the MB cake washed with PBS solution $(2 \mathrm{~mL}, \mathrm{pH} 7.4 \pm 0.1)$ which was again removed following centrifugation. The PTX-MB cake was again reconstituted in PBS solution (2 mL, pH $7.4 \pm$ 0.1 ), mixed for 5 min with an aqueous solution containing either biotin-Dox (5) or biotin-RB (6) $(1 \mathrm{~mL}, 5 \mathrm{mg} / \mathrm{mL})$ and centrifuged (100 rcf) for $3 \mathrm{~min}$. Following removal of the infranatant, the MB cake was then washed with PBS $(2 \mathrm{~mL}, \mathrm{pH}=7.4 \pm 0.1)$, centrifuged and the MB cake isolated. This washing / centrifugation procedure was repeated twice further with the final PTXDox MB / PTX-RB MB cake reconstituted in $2 \mathrm{~mL}$ of PBS. The final MB number was determined on a haemocytometer using an optical microscope. Size distribution analysis was carried out using imageJ image analysis software. MBs were sparged with oxygen gas for 2 min immediately prior to use. Fluorescence imaging of PTX-RB MB and PTX-DOX MB were performed using a Nikon Eclipse E400 epi-fluorescence microscope equipped and the G-2A longpass emission filter set $\left(\lambda_{\mathrm{EX}} 510-560,80 \%\right.$ transmission with a $590 \mathrm{~nm}$ cut-on wavelength of the longpass emission). The drug loading on the surface of the MBs was determined using UV-Vis spectroscopy for 5 and 6 measuring the intensity at $480 \mathrm{~nm}$ or $560 \mathrm{~nm}$ respectively. Samples were prepared by firstly destructing (bursting) the MB using an ultrasound bath before removing a known volume and diluting with PBS. The drug loading for 7 was determined using reverse phase HPLC, using a Phenomenex $\mathrm{C}_{18}$ column $(250 \times 4.6 \mathrm{~mm}, 5$ $\mu \mathrm{m})$, a mobile phase consisting of acetonitrile: water $(50: 50 \mathrm{v} / \mathrm{v})$, a flow rate of $1.5 \mathrm{~mL} / \mathrm{min}-1$ using $227 \mathrm{~nm}$ as the detection wavelength. The loading of PTX was calculated by the following equation: loading = amount of PTX loaded into the MB / total amount of lipid material $\times 100 \%$. 


\subsection{Clonogenic assay to determine the cytotoxicity of Dox, PTX, SDT and combinations}

of each in MCF-7 cells: The human breast adenocarcinoma cell line (MCF-7) was cultured in DMEM supplemented with $10 \%$ FBS, $100 \mu \mathrm{g} / \mathrm{ml}$ streptomycin and maintained in a humidified, $5 \% \mathrm{CO}_{2}$ atmosphere at $37^{\circ} \mathrm{C}$. MCF-7 cells were seeded $\left(5 \times 10^{3}\right)$ into each well of a 96 well plate and $24 \mathrm{~h}$ later cells were treated with PTX (1nM), Dox (10nM), RB (10nM) or combinations thereof for $3 \mathrm{~h}$, followed by medium replacement. Selected wells were treated with ultrasound for $30 \mathrm{~s}$ delivered using a Sonidel SP100 sonoporator using a frequency of 1 $\mathrm{MHz}$, an US power density of $3.0 \mathrm{~W} / \mathrm{cm}^{2}$ and a duty cycle of $50 \%$ (pulse frequency $=100 \mathrm{~Hz}$ ). After $18 \mathrm{~h}$, cells were pooled from 2 wells and seeded in a 6 well plate containing $5 \mathrm{ml}$ of complete media. Plates were placed in an incubator for 7 days. Medium was removed from wells and fixation/staining solution $(1 \mathrm{~mL})$ [consisting of crystal violet $(0.05 \% \mathrm{w} / \mathrm{v})$, formaldehyde $(2.7 \% \mathrm{v} / \mathrm{v})$, PBS $(10 \% \mathrm{v} / \mathrm{v})$, methanol $(1 \% \mathrm{v} / \mathrm{v})$ and distilled water $(86.3 \% \mathrm{v} / \mathrm{v})]$ was added to each well at room temperature for $20 \mathrm{~min}$. The solution was removed and wells were washed with water. Digital photographs were taken using a Canon EOS100D DSLR and colony formation was analysed using Image $\mathrm{J}$ software.

2.5 Preparation of 3D MCF-7 spheroids: Spheroids were generated by growing MCF-7 cells in 96 well Carrier Plates (ULA) from PerkinElmer. Cells were seeded $\left(8 \times 10^{3}, 100 \mu \mathrm{L}\right)$ in selected wells. After $24 \mathrm{~h}, 100 \mu \mathrm{l}$ of medium was added to each well and plates were incubated at $37^{\circ} \mathrm{C}$ in a humidified $5 \% \mathrm{CO}_{2}$ atmosphere for a further 3 days to allow the cells to aggregate. Medium was replenished every 3 days by removing $100 \mu \mathrm{L}$ of old media and replacing it with $100 \mu \mathrm{L}$ of fresh media.

\subsection{Chemo-sonodynamic therapy treatment of MCF-7 Spheroids using $O_{2} M B-P T X-D o x$}

/ $\mathbf{O}_{2} M B-P T X-R B \pm$ ultrasound: Three days after seeding, spheroids were allocated to groups and treated according to the following conditions: untreated (drug-free medium), $\mathrm{O}_{2} \mathrm{MB}$ (no drugs), PTX/Dox only $([\mathrm{PTX}]=0.34 \mu \mathrm{M},[\mathrm{Dox}]=1 \mu \mathrm{M})$, and $\mathrm{O}_{2} \mathrm{MB}-\mathrm{PTX}-\mathrm{Dox} / \mathrm{O}_{2} \mathrm{MB}-\mathrm{PTX}-\mathrm{RB}$ $([D o x]=1 \mu \mathrm{M},[R B]=10 \mu \mathrm{M})$. Where required, individual wells were then placed in direct contact with the emitting surface of a Sonidel SP100 sonoporator with US gel used to mediate 
contact. Each well was treated with US for $30 \mathrm{~s}$ using a frequency of $1 \mathrm{MHz}$, an US power density of $3.0 \mathrm{~W} / \mathrm{cm}^{2}$ and a duty cycle of $50 \%$ (pulse frequency $=100 \mathrm{~Hz}$ ). Plates were incubated in a humidified $5 \% \mathrm{CO}_{2}$ atmosphere at $37^{\circ} \mathrm{C}$ for $3 \mathrm{~h}$ and then wells were washed 3 times with PBS before fresh medium was added. $48 \mathrm{~h}$ after treatment, 5 spheroids per replicate from each condition were collected in an Eppendorf tube, washed with PBS and then incubated with trypsin/EDTA for $15 \mathrm{~min}$ at $37^{\circ} \mathrm{C}$. The resultant cellular suspension was then incubated for $3 \mathrm{~h}$ with MTT [10 $\mu \mathrm{l}(5 \mathrm{mg} / \mathrm{mL})$ in $100 \mu \mathrm{l}$ of medium). The absorbance was then measured at $570 \mathrm{~nm}$ using FLUOstar Omega microplate reader. Data were expressed as \% cell viability by comparison with untreated controls.

In addition to MTT analysis, propidium iodide (P.I.) staining was also performed to determine cellular damage to the spheroid corona. Following treatment, spheroids were washed 4 times with PBS to remove excess medium and then incubated with a solution of P.I. in PBS $(100 \mu \mathrm{g} / \mathrm{ml})$. Spheroids were then incubated in the dark at RT for 40 min and then washed 3 times with PBS to remove excess P.I. Micrographic images were recorded using a NIKON Eclipse E400 Phase contrast microscope in bright field and fluorescence modes (540 $\mathrm{nm}$ band pass excitation and $590 \mathrm{~nm}$ long pass emission filters). Image $\mathrm{J}$ software was used to quantify P.I. fluorescence and it was expressed as a \% of P.I. fluorescence intensity $/ \mu \mathrm{m}^{2}$, i.e. the P.I. fluorescence was normalized according to the area of the spheroid.

\subsection{Cytotoxicity of chemo-sonodynamic therapy in vivo using $\mathrm{O}_{2} \mathrm{MB}-\mathrm{PTX}-\mathrm{Dox} / \mathrm{O}_{2} \mathrm{MB}-$}

$\boldsymbol{P T X}-\boldsymbol{R B} \pm$ ultrasound: All animals employed in this study were treated humanely and in accordance with licenced procedures under the UK Animals (Scientific Procedures) Act 1986. MCF-7 cells $\left(5 \times 10^{6}\right)$ in $100 \mu \mathrm{L}$ Matrigel were sub-cutaneously implanted into the rear dorsum of 8-week old female SCID (C.B-17/IcrHan®Hsd-Prkdcscid) mice. Palpable tumours appeared approximately $1-2$ weeks after cell implantation. Once tumours became palpable, dimensions were measured using Vernier callipers. Tumour volume was calculated using the equation: tumour volume $=\left(\right.$ length $\mathrm{x}$ width $\left.{ }^{2}\right) / 2$. Once tumours reached approximately $65 \mathrm{~mm}^{3}$ animals were separated into the following groups: Group 1 remained untreated, groups 2 and 3 received an intravenous (IV) injection (50 $\mu \mathrm{L})$ of a mixed suspension of $\mathrm{O}_{2}$ MB-PTX-RB and 
$\mathrm{O}_{2}$ MB-PTX-Dox $\left(6.18 \times 10^{7} \mathrm{MB},[\mathrm{PTX}]=1.13 \pm 0.16 \mathrm{mg} / \mathrm{kg},[\mathrm{RB}]=2.63 \pm 0.35 \mathrm{mg} / \mathrm{kg},[\mathrm{Dox}]\right.$ $=0.97 \pm 0.15 \mathrm{mg} / \mathrm{kg}$ with (group 2) or without (group 3) ultrasound exposure. Group 4 received an I.V injection $(100 \mu \mathrm{L})$ of a Cremophor suspension containing PTX $(4.7 \mathrm{mg} / \mathrm{kg})$ and Dox (2.5 mg / kg). Ultrasound was administered directly to the tumour site using a Sonidel SP100 sonoporator $\left(3.5 \mathrm{Wcm}^{-2}, 1 \mathrm{MHz}, 30 \%\right.$ duty cycle, and PRF $=100 \mathrm{~Hz}$; PNP $=0.48 \mathrm{MPa}$; M.I. = 0.48) during, and $30 \mathrm{~min}$ after IV administration (for a total of $7.0 \mathrm{~min}$ ) using ultrasound gel to mediate contact. Animals were treated on days 0,7 and 21 and both the tumour volume and body weight measurements recorded at the indicated times.

2.8 Statistical Analysis: Error was reported as \pm standard error of the mean. Statistical analysis was undertaken using a GraphPad Prism software package (IBM, UK). Group-wise comparisons were made using one-sided parallel group t-tests with a $p$-value less than 0.05 deemed significant.

3.0 Results and Discussion: In advance of preparing and testing the drug loaded $\mathrm{O}_{2} \mathrm{MBs}$, we were first interested in determining the effectiveness of combining PTX, Dox and SDT on the treatment of MCF-7 cells. In this study, the concentration of each individual drug used was intentionally sub-lethal (i.e. drug concentrations that had no impact on cell viability), so that any benefit obtained by the combination treatment could easily be identified. In addition, as the action of US can influence the cellular uptake of drugs due to sonoporation, cells treated with Dox or PTX were also exposed to US, to control for any potential effects as a result of US exposure during SDT treatment. ${ }^{19}$ Following treatment, cell viability was then determined using a clonogenic assay. The results are shown in Figure 1 and reveal no reduction in colony number for cells treated with a combination of PTX, Dox and RB in the absence of US compared to untreated cells. Treatment of cells with PTX + US, RB + US (i.e. SDT) or Dox + US reduced colony number by $7.3,18.8$ and $29.3 \%$ respectively compared to untreated cells, while cells treated with combined PTX, Dox and RB + US reduced the colony number by $44.0 \%$. The lack of efficacy for the combined drug cocktail in the absence of US was not surprising as sub-lethal doses of the drugs were used. However, the significant improvement 
in efficacy following exposure to US may result from a sonoporative effect that improves the uptake of these drugs. The fact that the greatest reduction in colony number was observed for the combined PTX, Dox and SDT treatment group indicates that these three treatments complement each other and improve the overall cytotoxic effect observed.

Encouraged by these results, the next step was to incorporate the PTX, Dox and RB into the MB delivery vehicle. Two MB formulations were prepared (Figure 2): the first comprised PTX loaded in the hydrophobic acyl layer of the MB shell while biotin-Dox was attached to the $M B$ surface using the biotin-avidin linkage $\left(\mathrm{O}_{2} \mathrm{MB}-\mathrm{PTX}-\mathrm{Dox}\right)$; the second formulation also had PTX loaded in the MB shell but with biotin-RB attached to the MB surface $\left(\mathrm{O}_{2} \mathrm{MB}-\mathrm{PTX}-\mathrm{RB}\right)$.

To attach $\mathrm{RB}$ and Dox to the $\mathrm{O}_{2} \mathrm{MB}$ surface it was necessary to modify each compound to contain biotin functionality. We have described the preparation of biotin-RB before in a previous communication. ${ }^{11}$ However, the preparation of biotin-Dox has not yet been reported and was synthesised according to Scheme 1. Briefly, biotin (1) was first reacted with $N, N^{\prime}-$ disuccinimidyl carbonate (2) to form the corresponding NHS activated ester (3). Dox (4) was then attached to $\mathbf{3}$ via an amidation reaction to form the target compound biotin-Dox (5) which was isolated following preparative TLC purification and its structure confirmed using NMR and mass spectroscopy.

Following their preparation, $\mathrm{O}_{2} \mathrm{MB}-\mathrm{PTX}-\mathrm{Dox}$ and $\mathrm{O}_{2} \mathrm{MB}-\mathrm{PTX}-\mathrm{RB}$ were characterised using optical and fluorescence microscopy (Figure 3) while the drug loading was determined using UV-Vis spectroscopy (for RB and Dox) and HPLC (for PTX). Analysis of optical microscope images confirmed the presence of spherical $\mathrm{O}_{2} \mathrm{MB}-\mathrm{PTX}-\mathrm{Dox}$ and $\mathrm{O}_{2} \mathrm{MB}-\mathrm{PTX}-\mathrm{RB}$ microbubbles with mean particle diameters of $2.82 \pm 0.05$ and $2.61 \pm 0.02 \mu \mathrm{m}$ respectively and mean microbubble concentrations of $1.2 \times 10^{9}$ and $1.35 \times 10^{9} \mathrm{MB} / \mathrm{mL}$ respectively. Both $\mathrm{O}_{2} \mathrm{MB}-\mathrm{PTX}$-Dox and $\mathrm{O}_{2} \mathrm{MB}-\mathrm{PTX}-\mathrm{RB}$ also exhibited bright red fluorescent shells when analysed using fluorescent microscopy consistent with the successful attachment of the inherently fluorescent Dox and RB respectively (Figure 3). The mean loading of PTX, Dox and 
$\mathrm{RB}$ onto the MBs was determined to be $51.8 \pm 8.3 \mu \mathrm{g} / 10^{8} \mathrm{MBs}, 41.3 \pm 2.6 \mu \mathrm{g} / 10^{8} \mathrm{MBs}$ and $140.0 \pm 23.4 \mu \mathrm{g} / 10^{8} \mathrm{MBs}$ respectively. This reflects a loading for PTX of $23.5 \pm 1.8 \%$ which compares favourably with previous studies where PTX was loaded hydrophobically within the MB shell. ${ }^{20,}{ }^{21}$ One potential complication of loading PTX in the MB shell is that it could compromise the subsequent loading of biotinylated payloads to the MB surface. To determine if this was the case, batches of MBs with or without PTX in the shell were prepared and the ability to attach biotin-RB to the surface determined. The results are shown in Figure 4 and reveal no significant change in the loading of biotin-RB in the absence or presence of PTX. Indeed, the loadings achieved for both PTX and DOX using the approach adopted in this study suggest it would be possible to deliver clinically relevant doses of both agents PTX $\left(175 \mathrm{mg} / \mathrm{m}^{2}\right)$ and $\mathrm{DOX}\left(25 \mathrm{mg} / \mathrm{m}^{2}\right)$ as a part of the $\mathrm{MB}$ platform whilst remaining within the tolerated $\mathrm{MB}$ dose determined in primates (i.e. $3.31 \times 10^{11} \mathrm{MBs}$ to deliver $175 \mathrm{mg} / \mathrm{m}^{2} \mathrm{PTX}$ and $0.609 \times 10^{11}$ MBs to deliver $\left.25 \mathrm{mg} / \mathrm{m}^{2} \mathrm{DOX}\right) .{ }^{22}$ Off course, targeting delivery using UTMD means it should be possible to use much lower concentrations of these toxic chemotherapy drugs while maintaining an effective therapeutic outcome.

Having successfully prepared and characterised the $\mathrm{O}_{2} \mathrm{MB}-\mathrm{PTX}-\mathrm{Dox}$ and $\mathrm{O}_{2} \mathrm{MB}-\mathrm{PTX}-$ RB conjugates, the next step was to determine their efficacy in a 3D spheroid model of breast cancer. This model was chosen over the more conventional two-dimensional (2D) cellular monolayer as the heterogeneous architecture of a 3D spheroid more closely resembles that of in vivo solid tumours and thus is a valuable tool in the screening of new drugs and drug delivery systems. ${ }^{23}$ Spheroids were treated with $\mathrm{O}_{2} \mathrm{MB}$ only (i.e. no drugs attached), PTX / Dox only (i.e. not MB bound) and the $\mathrm{O}_{2} \mathrm{MB}-\mathrm{PTX}-\mathrm{Dox} / \mathrm{O}_{2} \mathrm{MB}-\mathrm{PTX}-\mathrm{RB}$ conjugates in the presence and absence of US. Untreated spheroids and spheroids treated with US only were also included for comparative purposes. Following treatment, the extent of cell viability was determined using an MTT assay and also by staining the spheroids with propidium iodide (P.I.) following treatment. 
Results from the MTT assay are shown in Figure 5 and reveal a moderate reduction in the viability of cells following exposure to US alone $(28.03 \%, p<0.05)$, which was similar to the reduction observed for the $\mathrm{O}_{2} \mathrm{MB}+\mathrm{US}$ treatment $(29.40 \%)$. Treatment of PTX / Dox alone reduced viability by $21.98 \%(p<0.05)$ relative to untreated spheroids, which was broadly unchanged in the presence of ultrasound (23.67\%). However, when spheroids were treated with the $\mathrm{O}_{2} \mathrm{MB}-\mathrm{PTX}-\mathrm{Dox} / \mathrm{O}_{2} \mathrm{MB}-\mathrm{PTX}-\mathrm{RB}$ conjugates and US, the cell viability decreased by $72.6 \%$ which was significantly greater than treatment with the $\mathrm{O}_{2} \mathrm{MB}-\mathrm{PTX}-\mathrm{Dox} / \mathrm{O}_{2} \mathrm{MB}-\mathrm{PTX}-$ RB conjugates in the absence of US (8.2\%) or the other groups. This improved cytotoxicity is most likely due to both SDT and the ability of $\mathrm{O}_{2} \mathrm{MB}$ induced cavitation to enhance dispersion of the drugs within the spheroid matrix. ${ }^{24}$ Indeed, MB cavitation is known to create associated microstreaming and microjetting events that have been attributed to improved tumour uptake and efficacy of chemotherapy drugs in several pre-clinical and clinical studies. ${ }^{25-27}$

Results from the P.I. staining experiments revealed a slightly different trend from those obtained using the MTT assay. P.I. is a DNA selective permeable dye that passes freely through compromised plasma membranes of dead cells and does not permeate the membrane of living cells. ${ }^{28}$ In contrast to the MTT assay experiments, where a single cell suspension of cells derived from spheroids was analysed post-treatment, intact spheroids were examined following treatment using P.I. staining. The brightfield and fluorescent images from each treatment group are shown in Figure 6a with the fluorescence intensity quantified and plotted in Figure 6b. Bright red P.I. fluorescence was observed for spheroids treated with the $\mathrm{O}_{2} \mathrm{MB}-\mathrm{PTX}-\mathrm{Dox} / \mathrm{O}_{2} \mathrm{MB}-\mathrm{PTX}-\mathrm{RB}+\mathrm{US}$ group which was significantly more intense than any of the other groups. It was also noticed that the mean volume of spheroids treated with $\mathrm{O}_{2} \mathrm{MB}$ PTX-Dox $/ \mathrm{O}_{2} \mathrm{MB}-\mathrm{PTX}-\mathrm{RB}+\mathrm{US}$ was significantly smaller than in any of the other groups including those spheroids treated with $\mathrm{O}_{2} \mathrm{MB}-\mathrm{PTX}$-Dox / $\mathrm{O}_{2} \mathrm{MB}-\mathrm{PTX}-\mathrm{RB}$ in the absence of US. Combined, the intense P.I. fluorescence and size reduction observed for spheroids treated with $\mathrm{O}_{2} \mathrm{MB}$ mediated chemo-sonodynamic therapy, in addition to the reduced cell viability 
observed from the MTT assay experiments, highlight the effectiveness of this treatment in this particular model of breast cancer.

While encouraged by the results obtained from the 3D spheroid experiments, the full utility of $\mathrm{O}_{2} \mathrm{MBs}$ as a delivery vehicle can only be determined in vivo. To this end, subcutaneous MCF-7 tumours were established in recipient mice and a mixed suspension of the $\mathrm{O}_{2} \mathrm{MB}-\mathrm{PTX}$-Dox / $\mathrm{O}_{2} \mathrm{MB}-\mathrm{PTX}-\mathrm{RB}$ formulations was administered to animals by IV injection. During injection, US was positioned at the tumour to disrupt the $\mathrm{O}_{2} \mathrm{MB}$, release the payloads and activate SDT, where appropriate. To evaluate the effectiveness of the $\mathrm{O}_{2} \mathrm{MB}$ delivered treatments, a group of animals were also treated with a combination of free PTX / Dox (i.e. not $\mathrm{O}_{2} \mathrm{MB}$ attached). The tumour growth delay plot is shown in Figure 7 and reveals a significant reduction in tumour volume for animals treated with $\mathrm{O}_{2} \mathrm{MB}-\mathrm{PTX}-\mathrm{Dox} / \mathrm{O}_{2} \mathrm{MB}-\mathrm{PTX}-\mathrm{RB}+\mathrm{US}$, with tumours still $11.44 \%$ smaller than the pre-treatment size 25 days after the initial treatment. In contrast, tumours in animals treated with the same $\mathrm{O}_{2} \mathrm{MB}-\mathrm{PTX}-\mathrm{Dox} / \mathrm{O}_{2} \mathrm{MB}-\mathrm{PTX}-\mathrm{RB}$ formulation in the absence of ultrasound increased in volume by $40.47 \%$ over the same time period. Indeed, the effect of $\mathrm{O}_{2} \mathrm{MB}-\mathrm{PTX}-\mathrm{Dox} / \mathrm{O}_{2} \mathrm{MB}-\mathrm{PTX}-\mathrm{RB}+\mathrm{US}$ was also significantly better than that observed following treatment using the free PTX / Dox combination which increased in volume by $18.90 \%$ at day 25 , despite receiving a $16.8 \%$ and $98.4 \%$ increased dose of PTX and Dox respectively. Combined, these results corroborate the in vitro efficacy results and highlight the effectiveness of $\mathrm{O}_{2} \mathrm{MB}$ delivered chemo-sonodynamic therapy as a targeted treatment for breast cancer. In addition to the improved efficacy offered by this approach, the treatment was also well tolerated with the body weight of animals in the $\mathrm{O}_{2} \mathrm{MB}$ treated groups mapping closely to that of untreated animals. In contrast, there was a $12.1 \%$ drop in bodyweight for animals treated with free PTX / Dox over the course of the experiment. This reduction in body weight most likely results from toxicity exhibited by the free drugs or the Cremophor EL vehicle required to deliver PTX. Cremophor EL is known to produce undesirable side-effects and while poorly tolerated, ${ }^{29-31}$ is necessary to enable the dispersion of hydrophobic PTX in aqueous solution. Therefore, the ability to avoid the use of such a toxic 
vehicle by incorporating PTX within the $\mathrm{O}_{2} \mathrm{MB}$ shell is an added advantage of the microbubblebased drug delivery system.

In conclusion, the use of $\mathrm{O}_{2} \mathrm{MBs}$ offer an attractive vehicle for the delivery of a chemosonodynamic therapy to solid breast tumours. The improved efficacy of $\mathrm{O}_{2} \mathrm{MB}$ delivered chemo-sonodynamic therapy, when compared to standard PTX / Dox treatment was demonstrated in both in vitro and in vivo models of the disease. In particular, the reduction in tumour volume, observed following treatment with $\mathrm{O}_{2} \mathrm{MB}$-delivered chemo-sonodynamic therapy, offers significant potential as a neo-adjuvant therapy to downstage tumours in advance of surgery, or, as a treatment for locally recurrent chest wall disease. An added advantage of this approach is that each component part of the treatment (i.e. the MBs, PTX, Dox, RB and US) has been safely used in humans previously thus providing the opportunity for rapid clinical translation.

Acknowledgements: JFC thanks Norbrook Laboratories Ltd for an endowed chair. KL thanks the Department for the Economy in Northern Ireland for a PhD studentship.

Data Availability: The raw/processed data required to reproduce these findings cannot be shared at this time due to legal reasons. 


\section{References}

1. Cancer Research UK. https://www.cancerresearchuk.org/health-professional/cancerstatistics/statistics-by-cancer-type/breast-cancer (accessed 2 July 2018).

2. Lawrence G, Kearins O, Lagord C, Cheung S, Sidhu J, Sagar J. The Second All Breast Cancer Report. http://www.ncin.org.uk/view.aspx?rid=612 (accessed 2 July 2018).

3. Mieog JS, van der Hage JA, van de Velde CJ. Neoadjuvant chemotherapy for operable breast cancer. The British Journal of Surgery 2007; 94(10): 1189-1200.

4. Kiebert GM, de Haes JC, van de Velde CJ. The impact of breast-conserving treatment and mastectomy on the quality of life of early-stage breast cancer patients: a review. Journal of Clinical Oncology 1991; 9(6): 1059-1070.

5. Early Breast Cancer Trialists' Collaborative Group (EBCTCG). Long-term outcomes for neoadjuvant versus adjuvant chemotherapy in early breast cancer: meta-analysis of individual patient data from randomised trials. The Lancet Oncology 2017; 19(1):27-29.

6. Perez EA. Doxorubicin and paclitaxel in the treatment of advanced breast cancer: efficacy and cardiac considerations. Cancer Investigation 2001; 19(2):155-164.

7. Mayer CR, Geis NA, Katus HA, Bekeredjian R. Ultrasound targeted microbubble destruction for drug and gene delivery. Expert Opinion on Drug Delivery 2008; 5(10):1121-1138.

8. Villarraga HR, Foley DA, Mulvagh SL. Contrast echocardiography 1996. A review. Texas Heart Institute 1996; 23(2):90-97.

9. Stride E, Saffari N. Microbubble ultrasound contrast agents: A review. Proceedings of the Institution of Mechanical Engineers, Part H: Journal of Engineering in Medicine 2003; 217(6):429-447. 
10. McEwan C, Kamila S, Owen J, Nesbitt H, Callan B, Borden M, et al. Combined sonodynamic and antimetabolite therapy for the improved treatment of pancreatic cancer using oxygen loaded microbubbles as a delivery vehicle. Biomaterials 2016; 80:20-32.

11. Nomikou N, Fowley C, Byrne NM, McCaughan B, McHale AP, Callan JF. Microbubblesonosensitiser conjugates as therapeutics in sonodynamic therapy. Chemical Communications 2012; (67):8332-8334.

12. McCaughan B, Rouanet C, Fowley C, Nomikou N, McHale AP, McCarron PA, Callan JF. Enhanced ROS production and cell death through combined photo- and sono-activation of conventional photosensitising drugs. Bioorganic and Medicinal Chemistry Letters 2011; 21(19): 5750-5752.

13. McEwan C, Fowley C, Nomikou N, McCaughan B, McHale AP, Callan JF. Polymeric Microbubbles as Delivery Vehicles for Sensitizers in Sonodynamic Therapy. Langmuir 2014; 30(49): 14926-14930.

14. Sugita N, Iwase Y, Yumita N, Ikeda T, Umemura S. Sonodynamically induced cell damage using rose bengal derivative. Anticancer Research 2010; 30(9): 3361-3366.

15. McEwan C, Owen J, Stride E, Fowley C, Nesbitt H, Cochrane D, et al. Oxygen carrying microbubbles for enhanced sonodynamic therapy of hypoxic tumours. Journal of Controlled Release 2015; 203:51-56.

16. Nesbitt H, Sheng Y, Kamila S, Logan K, Thomas K, Callan B, et al. Gemcitabine loaded microbubbles for targeted chemo-sonodynamic therapy of pancreatic cancer. Journal of Controlled Release 2018; 279: 8-16.

17. R. M. Straubinger, "Biopharmaceutics of paclitaxel (Taxol): formulation, activity and pharmacokinetics," in Taxol: Science and Applications, M. Suffness, Ed., pp. 237-258, CRC Press, 1996. 
18. Susumu K, Uyeda HT, Medintz IL, Pons T, Delehanty JB, Mattoussi H. Enhancing the Stability and Biological Functionalities of Quantum Dots via Compact Multifunctional Ligands. Journal of the American Chemical Society 2007; 129(45): 13987-13996.

19. Dimcevski G, Kotopoulis S, Bjånes T, Hoem D, Schjøtt J, Gjertsen BT, et al. A human clinical trial using ultrasound and microbubbles to enhance gemcitabine treatment of inoperable pancreatic cancer. Journal of Controlled Release 2016; 243: 172-181.

20. Luo T, Sun J, Zhu S, He J, Hao L, Xiao L, et al. Ultrasound-mediated destruction of oxygen and paclitaxel loaded dual-targeting microbubbles for intraperitoneal treatment of ovarian cancer xenografts. Cancer Letters 2017; 391: 1-11.

21. Xing W, Gang WZ, Yong Z, Yi ZY, Shan XC, Tao RH. Treatment of xenografted ovarian carcinoma using paclitaxel-loaded ultrasound microbubbles. Academic Radiology 2008; 15(12): 1574-1579.

22. Unger EC, Porter T, Culp W, Labell R, Matsunaga T, Zutshi R. Therapeutic applications of lipid-coated microbubbles. Advanced Drug Delivery Reviews 2004; 56(9): 1291-314.

23. Wen Z, Liao Q, Hu Y, You L, Zhou L, Zhao Y. A spheroid-based 3-D culture model for pancreatic cancer drug testing, using the acid phosphatase assay. Brazilian Journal of Medical and Biological Research 2013; 46(7): 634-342.

24. Karshafian R, Bevan PD, Williams R, Samac S, Burns PN. Sonoporation by ultrasoundactivated microbubble contrast agents: effect of acoustic exposure parameters on cell membrane permeability and cell viability. Ultrasound in Medicine and Biology 2009; 35(5): 847-60.

25. Postema M, van Wamel A, Lancée CT, de Jong N. Ultrasound-induced encapsulated microbubble phenomena. Ultrasound in Medicine and Biology 2004; 30(6): 827-840. 
26. van Wamel A, Bouakaz A, Versluis M, de Jong N. Micromanipulation of endothelial cells: Ultrasound-microbubble-cell interaction. Ultrasound in Medicine and Biology 2004; 30(9): $1255-1258$.

27. van Wamel A, Kooiman K, Harteveld M, Emmer M, ten Cate FJ, Versluis M, de Jong N. Vibrating microbubbles poking individual cells: Drug transfer into cells via sonoporation. Journal of Controlled Release 2006; 112(2): 149-155.

28. Riccardi C, Nicoletti I. Analysis of apoptosis by propidium iodide staining and flow cytometry. Nature Protocols 2006; 1(3): 1458-61.

29. Rowinsky EK, Eisenhauer EA, Chaudhry V, Arbuck SG, Donehower RC. Clinical toxicities encountered with paclitaxel (Taxol). Seminars in Oncology 1993; 20:1-15.

30. Eisenhauer EA, ten Bokkel Huinink WW, Swenerton KD, Gianni L, Myles J, van der Burg ME, et al. European-Canadian randomized trial of paclitaxel in relapsed ovarian cancer: highdose versus low-dose and long versus short infusion. Journal of Clinical Oncology 1994; 12(12): 2654-2666.

31. Szebeni J, Muggia FM, Alving CR. Complement activation by Cremophor EL as a possible contributor to hypersensitivity to paclitaxel: an in vitro study. Journal of the National Cancer Institute 1998; 90 (4): 300-306. 


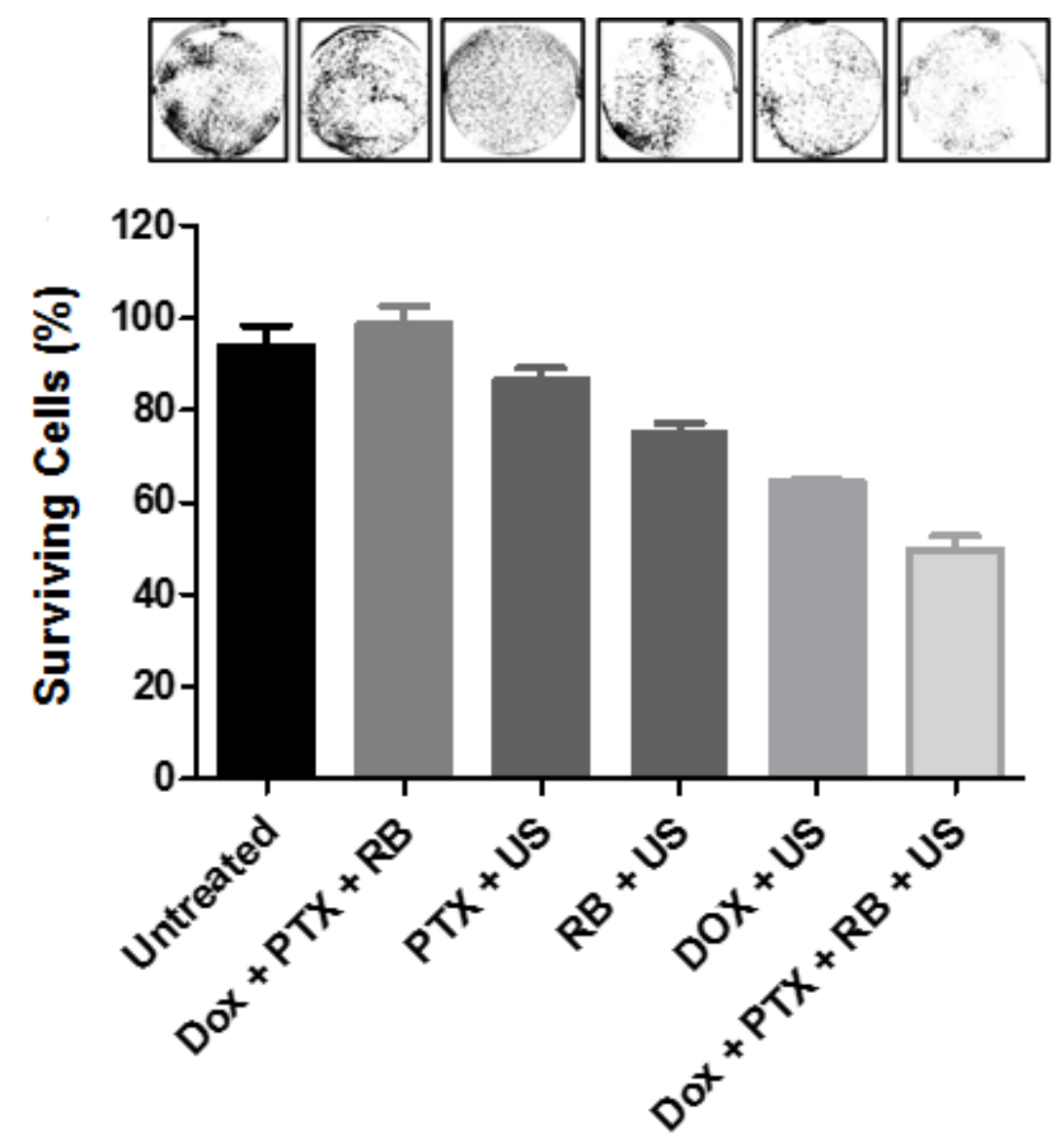

Figure 1. Plot showing \% of surviving MCF-7 cells for each of the treatment groups. Cells were treated with PTX +US (1nM), Dox +US (10nM), RB +US (10nM) and PTX + Dox + RB $+\mathrm{US}([\mathrm{PTX}]=1 \mathrm{nM},[\mathrm{Dox}]=10 \mathrm{nM},[\mathrm{RB}]=10 \mathrm{nM})$. After treatment, cells were incubated for 8 days followed by fixation and staining. Crystal violet staining of representative images are shown in the panel above each data bar. 
(a)

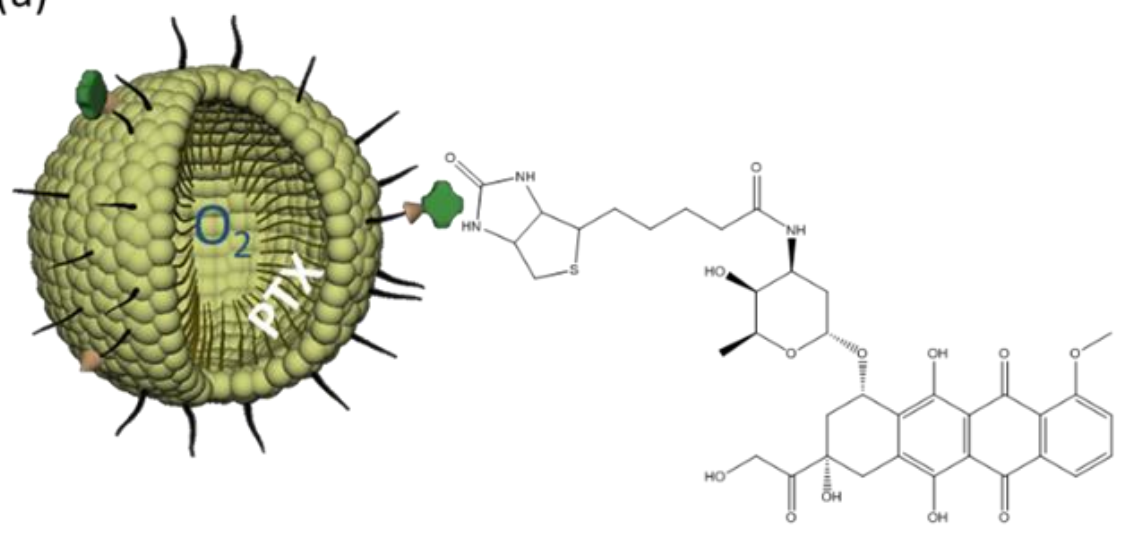

(b)
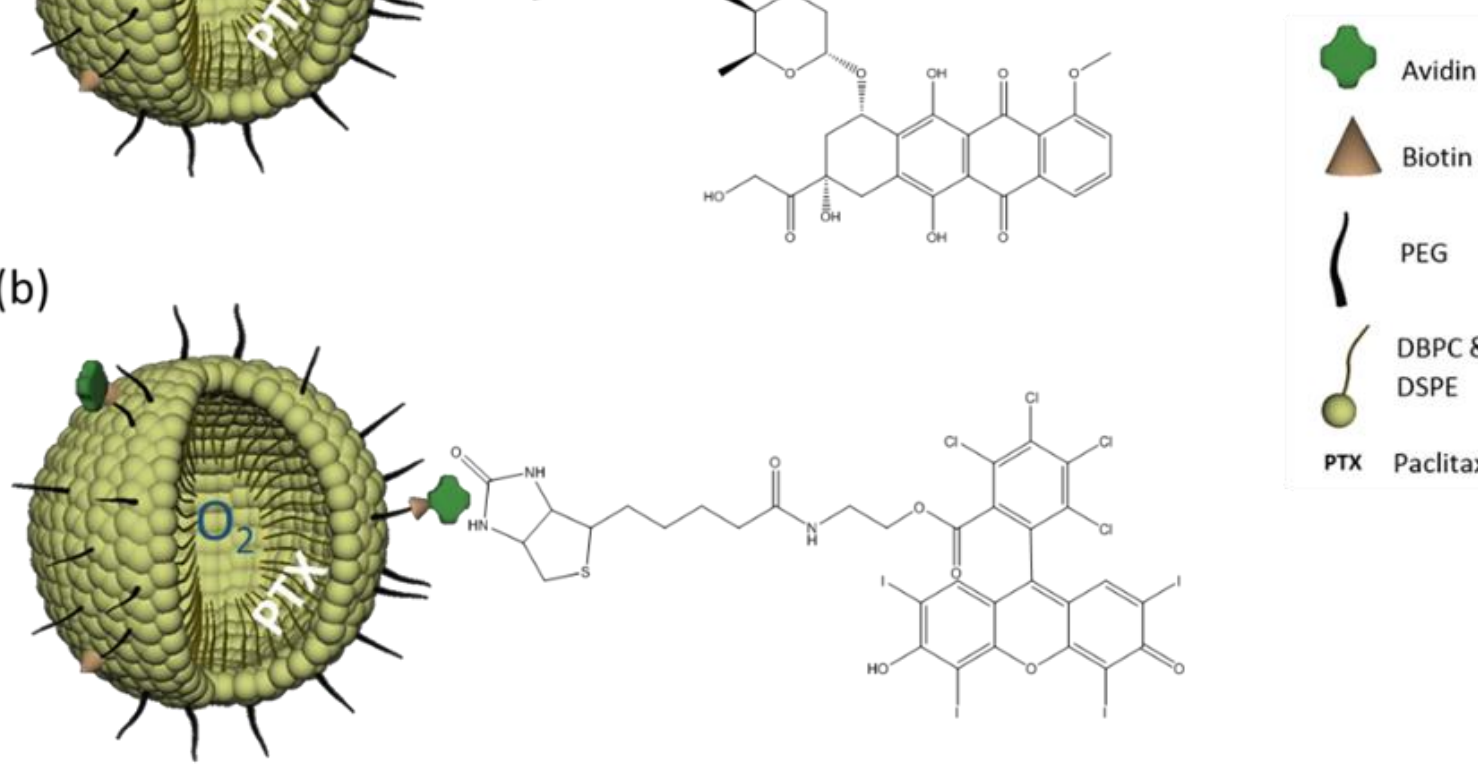

$\left\{\begin{array}{l}\text { DBPC \& } \\ \text { DSPE }\end{array}\right.$

PTX Paclitaxel

Figure 2. Schematic representation of (a) $\mathrm{O}_{2} \mathrm{MB}-\mathrm{PTX}$-DOX and (b) $\mathrm{O}_{2} \mathrm{MB}-\mathrm{PTX}-\mathrm{RB}$. 


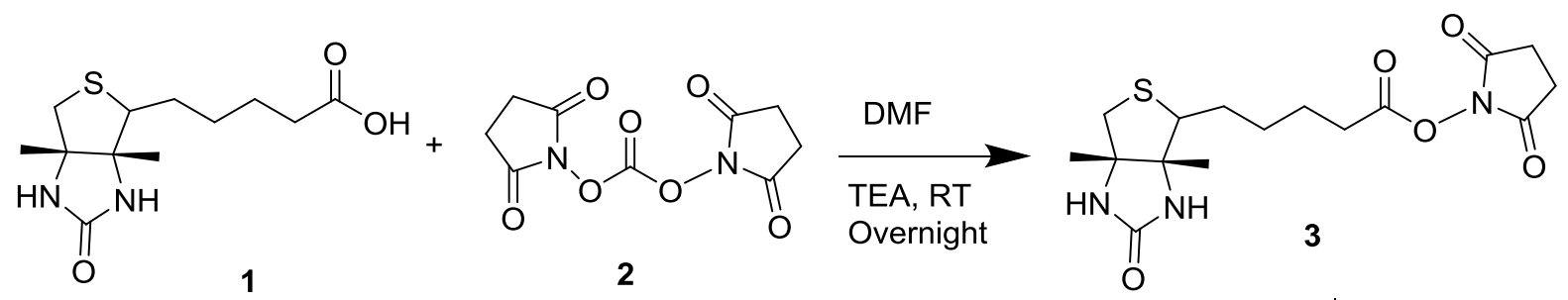<smiles>C[C@]12CSC(CCCCC(=O)NCCOC(=O)c3c(Cl)c(Cl)c(Cl)c(Cl)c3-c3c4c(O)c(I)c(=O)c(I)c-4oc4c(I)c(O)c(I)cc34)C1NC(=O)N2</smiles>

6

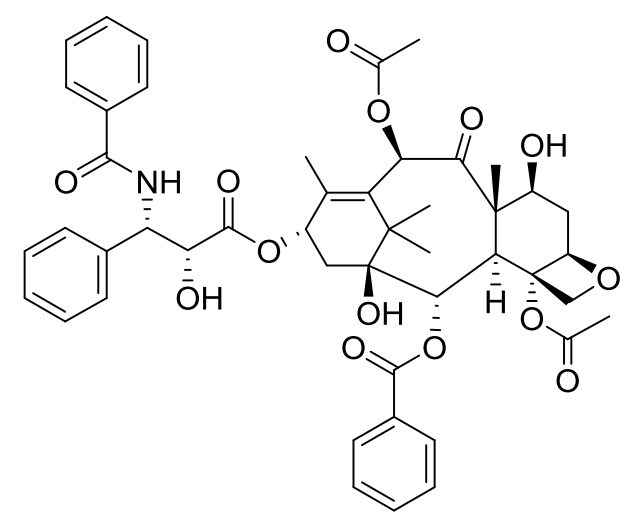

7
4<smiles>COc1cccc2c1C(=O)c1c(O)c3c(c(O)c1C2=O)C[C@@](O)(C(=O)CO)C[C@H]3O[C@H]1C[C@H](N)[C@@H](O)[C@H](C)O1</smiles>

Overnight<smiles>COc1cccc2c1C(=O)c1c(O)c3c(c(O)c1C2=O)C[C@@H](C(=O)CO)C[C@@H]3O[C@H]1C[C@@H](N)[C@H](O)[C@H](C)O1</smiles><smiles>C[C@]12NC(=O)N[C@@]1(C)CSC2CCCCC(N)=O</smiles>

5

Scheme 1. Synthetic scheme for the synthesis of biotin-Dox (5). Also shown are the structures of biotin-RB (6) and PTX (7). 
a)
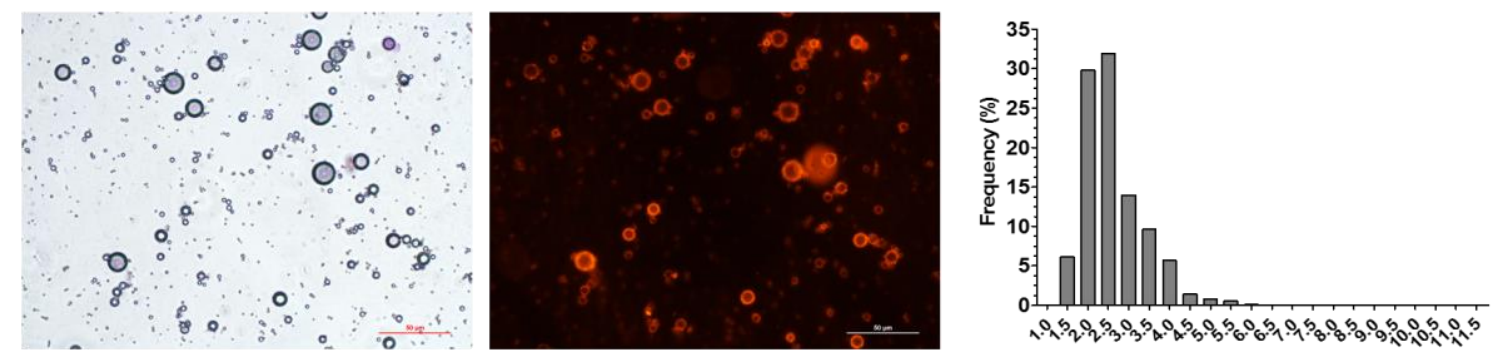

b)
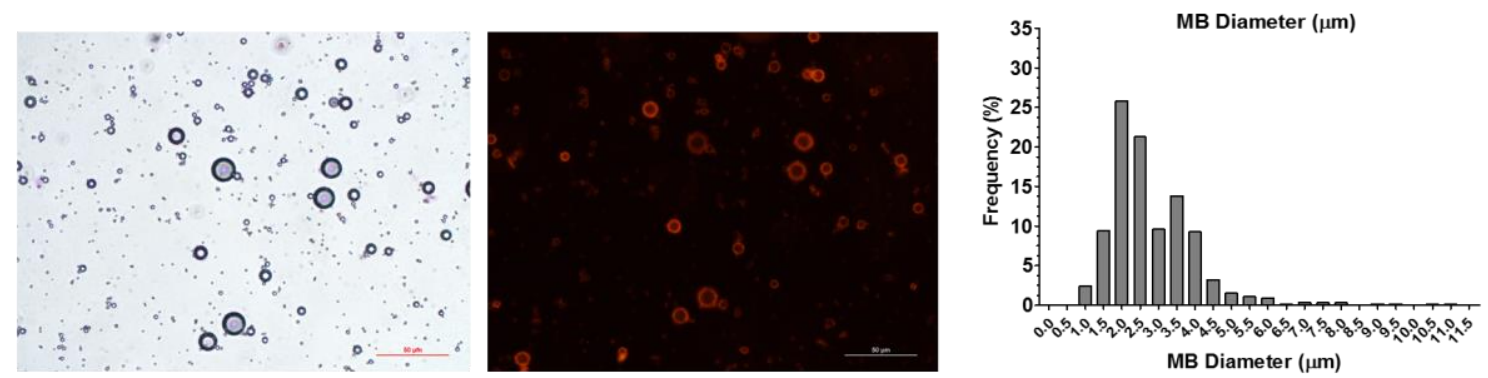

Figure 3. Representative bright field (left panel) and fluorescence (middle panel) micrographs and corresponding size distribution analyses (right panel) of (a) PTX-RB MB and (b) PTX-Dox MB. 


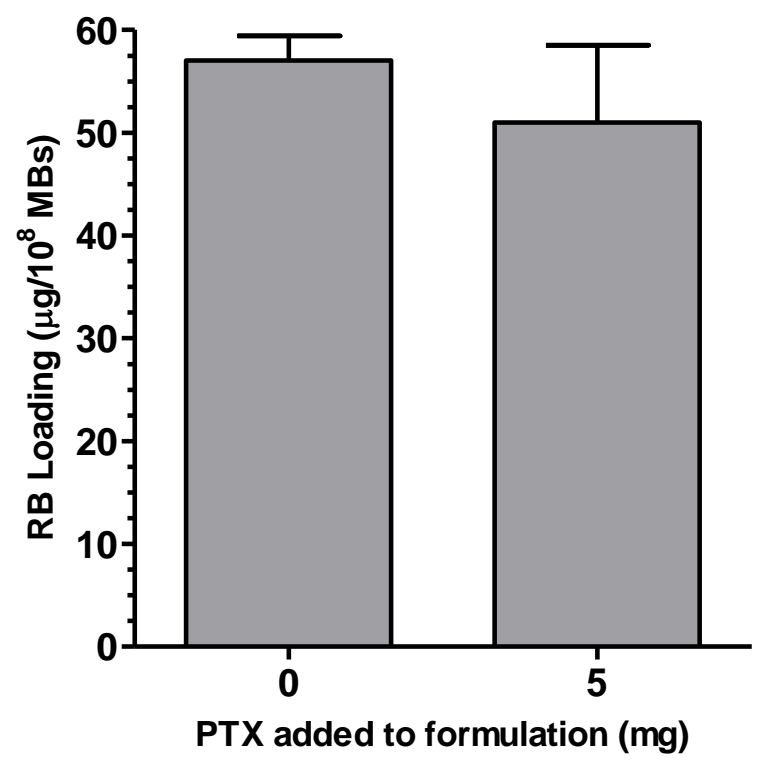

Figure 4. Plot of Rose Bengal loading (normalized to $10^{8} \mathrm{MBs}$ ) in the absence $(0 \mathrm{mg}$ ) and presence $(5 \mathrm{mg})$ of paclitaxel incorporated within the lipid layer during MB formulation (final PTX loading $\left.=51.8 \pm 8.3 \mu \mathrm{g} / 10^{8} \mathrm{MB}\right)$. 


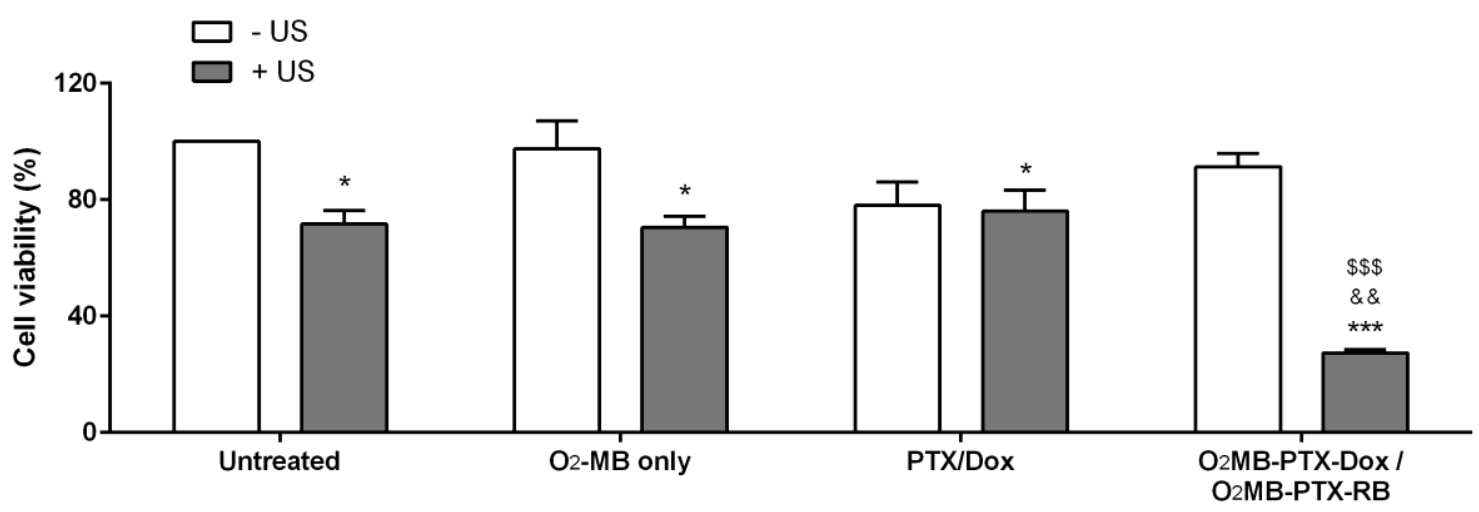

Figure 5. Plot of cell viability for 3D MCF-7 spheroids following exposure to (i) no treatment (ii) $\mathrm{O}_{2} \mathrm{MB}$ only (no drugs), (iii) PTX/Dox only (i.e. no $\mathrm{O}_{2} \mathrm{MBs}$ ) $([\mathrm{PTX}]=0.34 \mu \mathrm{M}$, [Dox] $=1 \mu \mathrm{M}$ ) or (iv) $\mathrm{O}_{2} \mathrm{MB}-\mathrm{PTX}-\mathrm{Dox} / \mathrm{O}_{2} \mathrm{MB}-\mathrm{PTX}-\mathrm{RB}([\mathrm{Dox}]=1 \mu \mathrm{M},[\mathrm{RB}]=10 \mu \mathrm{M})$ in the presence or absence of US.: ${ }^{*} p<0.05,{ }^{* *} p<0.001$ for treatment groups compared to untreated group. ${ }^{\&} \mathrm{p}<0.01$ for $\mathrm{O}_{2} \mathrm{MB}-\mathrm{PTX}-\mathrm{Dox} / \mathrm{O}_{2} \mathrm{MB}-\mathrm{PTX}-\mathrm{RB}+\mathrm{US} v \mathrm{PTX} / \mathrm{Dox}+\mathrm{US} . \quad{ }^{\$ \$ \$} \mathrm{p}<0.001$ for $\mathrm{O}_{2} \mathrm{MB}-$

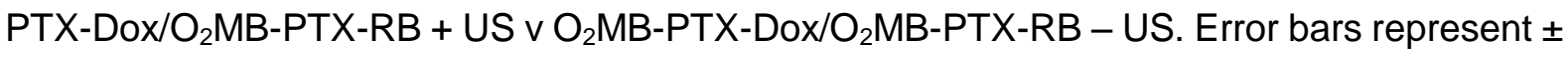
the standard error, $\mathrm{n}=3$. 
(a)

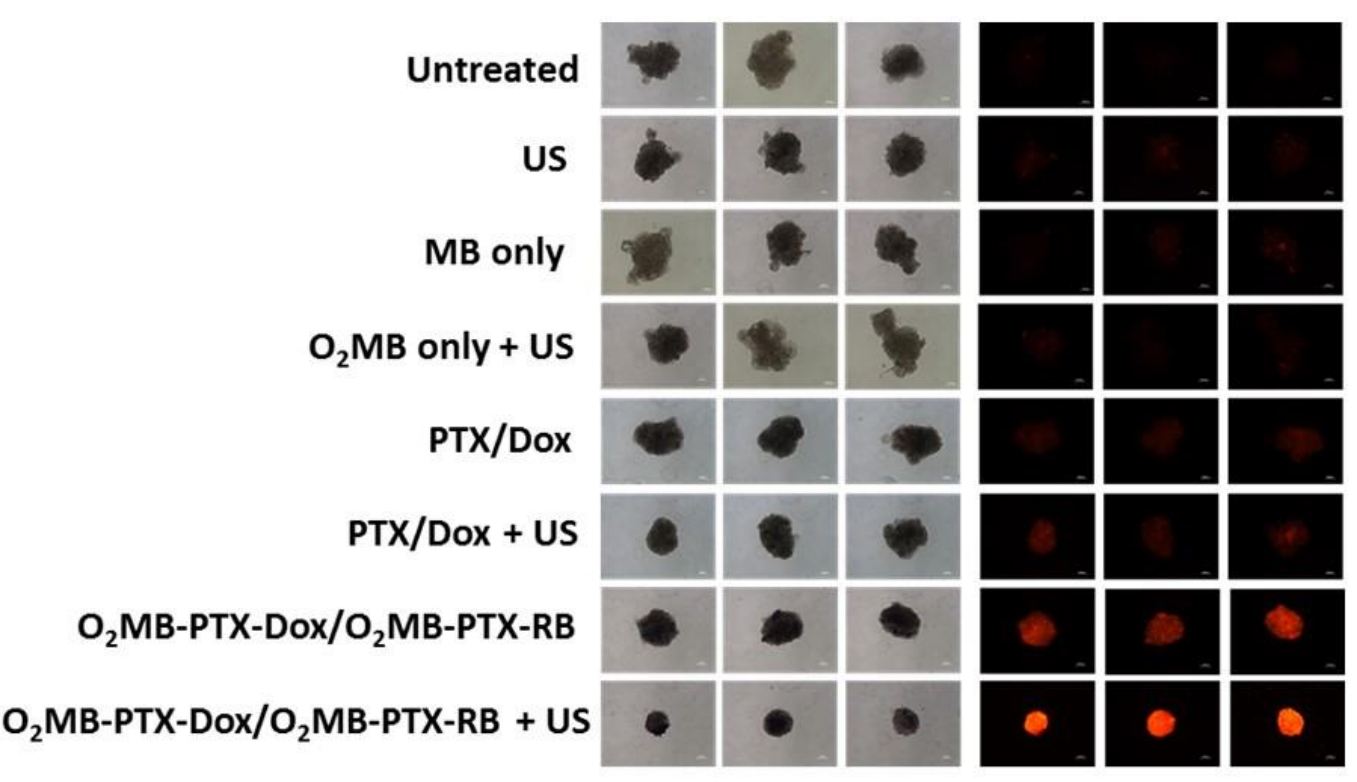

(b)

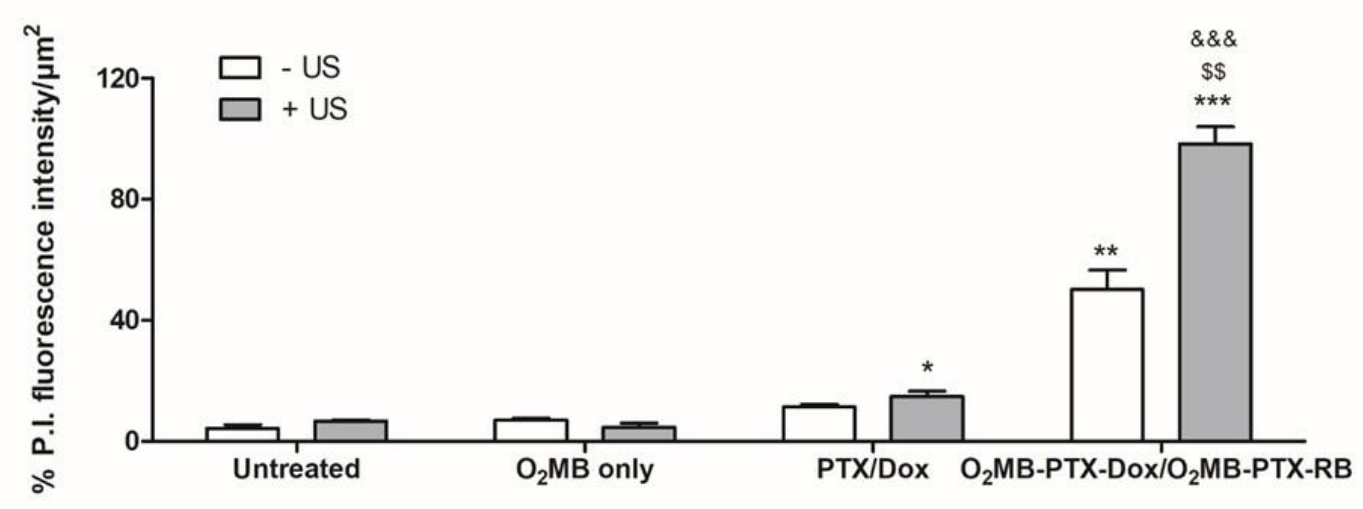

Figure 6. (a) Optical (left panel) and fluorescence (right panel) micrographs of MCF-7 spheroids exposed to: (i) no treatment, (ii) US only (iii) MB only, (iv) $\mathrm{O}_{2} M B+$ US (v) PTX/Dox only ([PTX] = $0.34 \mu \mathrm{M},[$ Dox] $=1 \mu \mathrm{M})$, (vi) PTX / Dox + US (vii) $\mathrm{O}_{2}$ MB-PTX-Dox / O $2 M B-P T X-$ $\mathrm{RB}([\mathrm{Dox}]=1 \mu \mathrm{M},[\mathrm{RB}]=10 \mu \mathrm{M})$ and (viii) $\mathrm{O}_{2} \mathrm{MB}-\mathrm{PTX}-$ Dox $/ \mathrm{O}_{2} \mathrm{MB}-\mathrm{PTX}-\mathrm{RB}+$ US. Spheroids were stained with P.I. following treatment. (b) plot of P.I. intensity per $\mu \mathrm{M}^{2}$ for each of the groups shown in (a) (normalized to $100 \%$ by comparison with $\mathrm{O}_{2}$ MB-PTX-Dox / $\mathrm{O}_{2}$ MB-PTX$R B+$ US group). ${ }^{*} p<0.05,{ }^{* *} p<0.01,{ }^{* * *} p<0.001$ significance for treatment groups relative to untreated group. ${ }^{\$ \$} \mathrm{p}<0.01$ significance for $\mathrm{O}_{2} \mathrm{MB}-\mathrm{PTX}-\mathrm{Dox} / \mathrm{O}_{2} \mathrm{MB}-\mathrm{PTX}-\mathrm{RB}+\mathrm{US} \vee \mathrm{O}_{2} \mathrm{MB}-$ PTX-Dox/O 2 MB-PTX-RB PTX/Dox + US. ${ }^{\text {\&\&\& }}$ < $<0.001$ significance for $\mathrm{O}_{2} \mathrm{MB}-\mathrm{PTX}-\mathrm{Dox} / \mathrm{O}_{2} \mathrm{MB}-$ PTX-RB + US v PTX/Dox + US. Error bars represent \pm the standard error, $n=3$. 
(a)

Untreated

- $\mathrm{O}_{2} \mathrm{MB}-\mathrm{PTX}-\mathrm{RB} / \mathrm{O}_{2} \mathrm{MB}-\mathrm{PTX}-\mathrm{DOX}+\mathrm{US}$

$\leftarrow \mathrm{O}_{2}$ MB-PTX-RB/O $\mathrm{O}_{2}$ MB-PTX-DOX - US

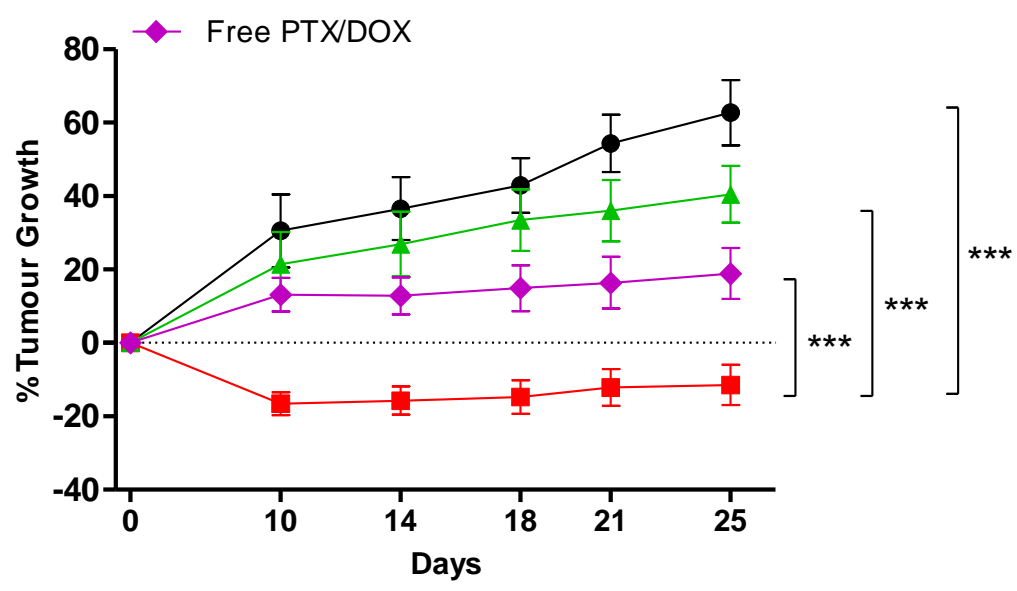

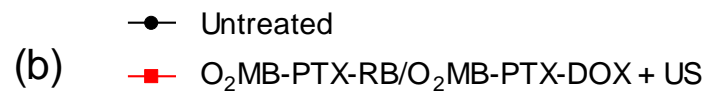

$\neg \mathrm{O}_{2}$ MB-PTX-RB/O MB-PTX-DOX - US

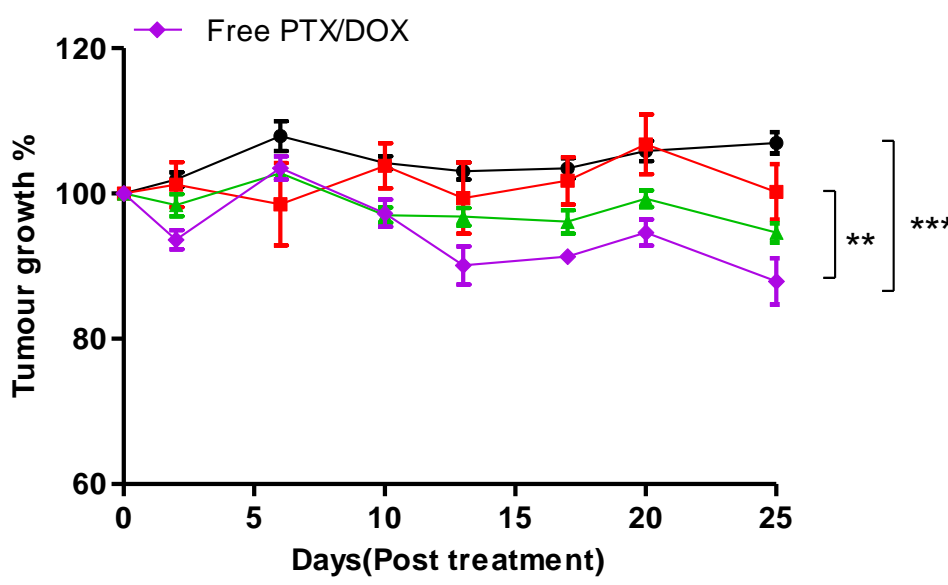

Figure 7. (a) Tumour growth delay plot for mice bearing MCF-7 xenograft tumours. Control animals received no treatment. Groups were treated with a mixed suspension $(50 \mu \mathrm{L})$ of $\mathrm{O}_{2}$ MB-PTX-RB and $\mathrm{O}_{2}$ MB-PTX-Dox $\left(6.18 \times 10^{7} \mathrm{MB},[\mathrm{PTX}]=1.13 \pm 0.16 \mathrm{mg} / \mathrm{kg},[\mathrm{RB}]=2.63 \pm\right.$ $0.35 \mathrm{mg} / \mathrm{kg}$, [Dox] $=0.97 \pm 0.15 \mathrm{mg} / \mathrm{kg}$ ) delivered by IV in the presence and absence of US.. A group was also treated with Cremophor EL suspension containing free PTX and Dox ([PTX] $=4.7 \mathrm{mg} / \mathrm{kg},[\mathrm{Dox}]=2.5 \mathrm{mg} / \mathrm{kg}$ ) (b) Plot of animal weights recorded over the course of the experiment for each group. For graphs (a) and (b) ${ }^{* *} p<0.01,{ }^{* * *} p<0.001$. Error bars represent \pm SEM where $n=5$. 